\title{
Guerras, libertad y ciudadanía. Los afro-descendientes de Esmeraldas en la independencia
}

\author{
por \\ Federica Morelli \\ Universidad de Turin \\ federica.morelli@unito.it
}

\begin{abstract}
El artículo analiza el papel jugado por la crisis del imperio español y de las guerras de independencia hispanoamericanas en la trasformación de las jerarquías raciales y sociales de la época colonial y en la configuración de nuevos derechos de ciudadanía. Estudiando el caso de Esmeraldas, una región de frontera al noroeste de Ecuador, se quiere poner en evidencia los variados mecanismos que los afro-descendientes, tanto esclavos como libres, utilizaron para acceder a la libertad y la ciudadanía durante el derrumbe de la Monarquía. Se trató de estrategias diferentes a las empleadas por los esclavos y libres de color en otras regiones de Hispanoamérica ya que respondieron a dinámicas propias de una región de frontera.
\end{abstract}

Palabras Clave: libres de color; esclavos; ciudadanía; independencia; Esmeraldas.

Este ensayo se propone analizar el papel jugado por la crisis del imperio español y de las guerras de independencia hispanoamericanas en la trasformación de las jerarquías raciales y sociales de la época colonial y en la configuración de nuevos derechos de ciudadanía. Mediante el estudio del caso de Esmeraldas, una región de frontera al noroeste de Ecuador, tiene por objetivo destacar los mecanismos que los afro-descendientes, tanto esclavos como libres, utilizaron para acceder a la libertad y ciudadanía durante el derrumbe de la monarquía. Se trata de dispositivos diferentes de los que los esclavos y libres de color emplearon en otras zonas de Hispanoamérica, propios de una región de frontera, alejada de los centros de poderes coloniales. En este área no hubo batallas importantes ni llegaron los representantes republicanos para 
reclutar en masa a los soldados. Sin embargo, los beneficios alcanzados por los esclavos y los libres de color fueron los mismos que en otros territorios de Hispanoamérica, es decir, un amplio proceso de liberación esclavista y de acceso a la ciudadanía.

Estas conclusiones fueron posibles gracias a los aportes de la reciente historiografía en torno a dos temáticas cruciales: primera, las independencias hispanoamericanas y sus nuevas interpretaciones; y, segunda, los grupos subalternos, en especial los descendientes de los africanos, y su desempeño como actores políticos. Respecto al primer punto, los estudios de los últimos treinta años han renovado completamente la interpretación de las independencias hispanoamericanas y de los estados nacionales cuya emergencia no es producto directo e inmediato de la ruina y desarticulación de la Monarquía Hispánica, sino el resultado de un proceso más amplio y complejo iniciado con las Abdicaciones de los Borbones en Bayona ${ }^{1}$. No asistimos entonces a un fenómeno lineal, caracterizado por el conflicto entre revolucionarios $\mathrm{y}$ realistas, sino mas bien a un proceso fragmentado y ecléctico, marcado por continuidades y discontinuidades en el cual las experiencias de un lado y otro del Atlántico se influenciaron mutuamente. No se trata, por lo tanto, de simples guerras anti-coloniales: las independencias hispanoamericanas se integran y analizan dentro de un proceso más amplio que es la crisis de los sistemas imperiales de la edad moderna. El español, en particular, representa la primera disolución de uno de esos grandes conjuntos pluri-comunitarios, muy frecuentes en al antiguo régimen, pero difíciles de concebir y gobernar una vez triunfante el modelo de Estado nacional ${ }^{2}$. No se asiste por lo tanto a un camino lineal que va de la búsqueda de la libertad contra la opresión colonial a la emancipación, sino a una crisis imperial que genera diferentes procesos locales y una gigantesca fragmentación territorial. Los espacios entorno a los cuales se formaron las nuevas naciones tuvieron una gestación muy lenta y difícil, marcada por guerras -internas y externas- y duras disputas ideológicas sobre la naturaleza de la nueva organización política y territorial.

La inserción de las revoluciones hispanoamericanas en un cuadro imperial y atlántico ha provocado no solo una ruptura evidente con la aproximación tradicional centrada en la nación, sino también la aparición de una nueva mirada al nacimiento de las repúblicas. A partir de allí, en lugar de ser consideradas un acontecimiento irrelevante o con características anómalas y alejadas de los

${ }^{1}$ La bibliografía sobre el tema es muy amplia. Los trabajos pioneros son los de: Guerra, 1992 y Rodríguez, 1996. En particular sobre el tema de los espacios borbónicos y su disolución en un contexto más amplio, véase Pinto, 2014: 9-168.

2 Annino, Guerra y Castro, 1994: 613-615. 
modelos revolucionarios norteamericano o francés, las referidas contribuciones las vinculan al nacimiento de la modernidad política, sobre todo en relación al tema de la ciudadanía democrática ${ }^{3}$. Su análisis es fundamental para enriquecer y complejizar el canon tradicional de las revoluciones atlánticas y el papel de los llamados sectores «subalternos» en la elaboración de las categorías de la modernidad ${ }^{4}$.

Respecto a la segunda cuestión historiográfica, hay que subrayar la significativa dimensión alcanzada por los estudios sobre los grupos hispanoamericanos de origen africano tanto esclavos como libres. Algo en evidente contraste con la postura prevaleciente hasta la década de 1980, cuando los ideales de la «democracia racial» y del mestizaje, junto al hecho de que en la América española la mayoría de la fuerza de trabajo estaba constituida por los indígenas, habían relegado a un segundo plano dicha temática. Este cambio ha sido acompañado y, en parte, precedido por el reconocimiento del carácter multiétnico y multicultural de numerosos estados latinoamericanos y de derechos particulares a las minorías en los textos constitucionales. Numerosos estudios dedicados a la América afro-latina revelaron rasgos importantes de las vidas de las sociedades afroamericanas insistiendo sobre los caracteres particulares de las poblaciones negras, su capacidad de acción (agency) y de auto-organización, su consciencia de grupo, y, más en general, la centralidad del factor racial en la estratificación social ${ }^{5}$.

El reconocimiento del papel de los africanos y sus descendientes en la formación de las sociedades latinoamericanas se debe también al desarrollo, en el ámbito anglosajón y en parte europeo, de la historia atlántica que estudia en términos de conexiones y convergencias las sociedades que se han construido, a partir de 1492, sobre la interacción -determinada también por la violencia- entre africanos, europeos e indígenas ${ }^{6}$. Gracias a la difusión de esta nueva perspectiva, la manera de abordar el estudio de los esclavos y libres de color ha cambiado con respecto a los años 60 y 70 del siglo pasado: en lugar de limitarse a analizar los aspectos más esencialmente sociales de su vida (como las tasas de manumisión, las de reproducción y de mortalidad, las actividades económicas, el patrimonio), a raíz de los estudios sobre la revolución haitiana, trabajos recientes han insistido en la dimensión política

\footnotetext{
3 Véase el balance de Morelli, 2004.

${ }^{4}$ Sobre este punto, véase Thibaud, Entin, Gómez y Morelli, 2013.

${ }^{5}$ La bibliografía sobre el tema es hoy muy amplia. Véase, de todos modos, los trabajos pioneros de Andrews, 1979; 2004.

${ }^{6}$ Sobre los rasgos de la nueva historia atlántica, véase Hancock, 1999. Baylin, 2005. Games, 2006.
} 
de su acción. Estos estudios han tenido un impacto notable sobre la historiografía de las independencias hispanoamericanas, ya que resaltaron el papel de los sectores populares en las guerras. Mientras la actuación de los indígenas, gracias a la historiografía marxista y a los aportes de la antropología, ha sido relativamente estudiada, los trabajos más recientes han integrado a los afroamericanos en los análisis sobre las independencias, mostrando como su actividad en la guerra fue decisiva para la victoria final sobre los españoles ${ }^{7}$. Los libres de color, en particular, desarrollaron un papel importante también en la difusión de los ideales del republicanismo, de la libertad e igualdad ${ }^{8}$.

Este ensayo se propone poner en dialogo dos corrientes historiográficas que tradicionalmente se han contrapuesto: la historia social, desde abajo, y la política, desde arriba. Mientras la primera suele conceder demasiada coherencia de actuación a un grupo definido por el estigma racial, la segunda no siempre atiende las cuestiones vinculadas a los grupos subalternos. Sin embargo, la confrontación entre estas dos corrientes se hace necesaria para comprender una de las particularidades de las revoluciones hispanoamericanas: la precoz y definitiva inclusión constitucional de las minorías de raza y de color en la ciudadanía civil y política y su acción decisiva en el proceso revolucionario y contrarrevolucionario. No obstante la situación de inferioridad de las poblaciones de color y de los indígenas se haya deteriorado en el curso del siglo XIX, esto no puede oscurecer el momento de su intensa participación y politización durante las guerras. Alejándose de las tesis poscoloniales, y adoptando sin embargo algunos de sus propósitos metodológicos relativos a la lectura de las fuentes, este articulo quiere mostrar como los grupos de color no eligieron el camino de una revolución «negra»o «indígena» posteriormente traicionada por los blancos. Más bien participaron activamente en un campo o en el otro (realista o republicano) en función de la lucha por la eliminación de sus incapacidades jurídicas, de la marginalización económica y de la indignidad moral que los afectaban. Antes de adentrarnos en el específico caso de Esmeraldas, se van a analizar las experiencias de ascenso político y social de otros grupos afro-descendientes acaecidas entre las reformas de la segunda mitad del siglo XVIII y la independencia, haciendo referencia, de manera particular, al caso de la Tierra Firme (Colombia e Venezuela). El objetivo es discutir el caso particular de los afro-descendientes de Esmeraldas dentro de un contexto más amplio, caracterizado por importantes cambios políticos y sociales que afectaron, de manera diferente, a todas las poblaciones de color del mundo hispanoamericano.

\footnotetext{
7 Bohiga, 1974: 102. Andrews, 1979: 116-117. Blanchard, 2008.

8 Sobre este tema, véase Helg, 2004. Lasso, 2007. Gómez, 2008.
} 


\section{REFORMAS Y GUERRAS: EL ACCESO DE LOS AFRO-DESCENDIENTES A LIBERTAD Y CIUDADANÍA}

Si bien la historiografía sobre las reformas borbónicas en Hispanoamérica tiene una importante trayectoria, en estos últimos veinte años son raras las obras dedicadas exclusivamente al periodo borbónico, siendo generalmente considerado como parte de una época más amplia que va desde la segunda mitad del siglo XVIII (la fin de la Guerra de los Siete Años en 1763) hasta la segunda mitad del XIX aproximativamente. Este periodo coincide, a su vez, con el difícil proceso de construcción y formación de los estados nacionales. El primero en proponer esta periodización fue el historiador argentino Tulio Halperín Donghi en 1985, quien sostenía que «las reformas acentuaron la fragmentación interna de la sociedad hispanoamericana» volviendo más dramática la herencia colonial ${ }^{9}$. Esta cronología se reveló muy pronto como guía fundamental para investigar las formaciones estatales de la primera mitad del siglo XIX, en especial para los estudios centrados en la historia política ${ }^{10}$.

Nuevas perspectivas sobre la época de las reformas han influenciado esta periodización. Mientras tradicionalmente habían sido consideradas un tentativo (y fracasado) caso de centralización del poder en las manos del monarca español y de sus ministros, hoy las opiniones sobre ellas están mucho más matizadas. En lugar de insistir sobre las resistencias al proyecto, centrando la atención en las revueltas y las medidas inaplicadas, los estudios más recientes subrayan como el programa borbónico no puede reducirse a un intento de la Corona de incrementar su control sobre los territorios coloniales y las entradas fiscales. Ello sucede porque: primero, los funcionarios coloniales y los mismos grupos americanos se reapropiaron de las políticas metropolitanas transformándolas y adaptándolas a sus intereses y necesidades; y, segundo, tal como propone Jeremy Adelman en su trabajo sobre el Atlántico ibérico, el acento, cuando se habla de reformas borbónicas, hay que ponerlo en el término de integración más que en el de centralización. Las reformas no lograron centralizar el poder, sino intentaron integrar los territorios americanos en una nueva idea de imperio, en el que la metrópoli se transformaba en nación y las provincias del antiguo orden imperial en colonias integradas en un sistema comercial atlántico ${ }^{11}$.

Analizar la independencia a partir de un arco cronológico más amplio implica además integrar las independencias hispanoamericanas en un contexto

\footnotetext{
${ }^{9}$ Halperín Donghi, 1985: 73.

${ }^{10}$ Véase, por ejemplo, Rodríguez, 1994. Tío Vallejo, 2001. Morelli, 2005. Adelman, 2006. Dym, 2007.

${ }^{11}$ Adelman, 2006: 54.
} 
más extenso, el Atlántico, imbuido entre 1763 y 1830 de una serie de revoluciones que modificaron radicalmente su escenario geo-político. El referente Atlántico permite vincular las independencias del continente americano no solo con las guerras y revoluciones europeas, sino también con el africano y sus problemáticas vinculadas al comercio de los esclavos y con la revolución haitiana. Esta última, en particular, ha jugado un papel importante en la difusión de las ideas sobre la abolición de la esclavitud (el miedo de sublevaciones de esclavos contra los blancos) en toda el área del Caribe, incluidas las costas meridionales de Estados Unidos, las mexicanas, venezolanas y colombianas ${ }^{12}$. La inserción de las independencias hispanoamericanas en el contexto atlántico favorece finalmente un aproche comparativo con las otras revoluciones de la época, de manera particular por lo que concierne el acceso a la libertad y la ciudadanía. La consideración del desenlace positivo de la independencia norteamericana respecto a las otras revoluciones de la época (y particularmente a las hispanoamericanas) han ocultado por mucho tiempo las similitudes entre estas experiencias: la continuidad de la esclavitud, la adhesión espontánea de muchos grupos coloniales a la autoridad real, la formación de milicias y la participación de esclavos y libres de color en las guerras, la dificultad de construir un estado frente a las tensiones centrifugas.

Antes de abordar el caso esmeraldeño, se considerarán rápidamente algunos de los mecanismos utilizados por los afro-descendientes de la América española para conseguir la libertad y la ciudadanía, es decir, la paridad jurídica con los blancos. Estos, como veremos, remiten inicialmente a la época borbónica para después transformarse y ampliarse durante las guerras de independencia. En la última fase de la época colonial, gracias a algunos mecanismos introducidos por las reformas, como la constitución de la milicias de pardos y morenos o las gracias al sacar, que permitían a los pardos comprar la «blancura», numerosos libres de color pudieron acceder a derechos y privilegios normalmente prohibidos a los de su clase. A las milicias de color, que ya existían desde el siglo XVI y que se difundieron en la mayoría de los territorios americanos después de 1763, les fue concedido el fuero militar, esto es, el privilegio jurisdiccional que las protegía de la justicia ordinaria, civil y criminal. El fuero no solo permitía recibir, durante las campañas de guerra un sueldo semanal (prest) ${ }^{13}$, sino atribuía también una dignidad particular en la medida en que este elemento era el fundamento jurídico del privilegio

12 Geggus, 2001; 2010. Gómez, 2013.

${ }^{13}$ Es a partir de esta ventaja que Lyman Johnson explica la participación masiva de los plebeyos de Buenos Aires a las milicias que rechazaron los ataques ingleses de 1806-07. Johnson, 2011: 249-266. 
de la nobleza en las Américas. Si bien las leyes limitaron el ascenso de los non blancos al grado de capitán, que no implicaba el acceso a la nobleza, la extensión del privilegio a los libres de color que las reformas provocaron es innegable. En este sentido, la hipótesis de una conciencia racial positiva, evocada por la historiografía norteamericana sobre las milicias de color, nos parece anacrónica. El objetivo de las castas no era la obtención de derechos en tanto grupo diferenciado de los otros, sino acceder a los mismos derechos y privilegios que los blancos. En un mundo en el que los cargos y los oficios más importantes estaban prohibidos para quienes no eran blancos, el acceso al privilegio permitía consolidar el estatus de vecino de un lugar, cancelando las incapacidades jurídicas que tocaban a los afro-descendientes. De la misma forma, la exención de algunos impuestos como el tributo identificaba una elite de color que se erigía arriba de la plebe.

Otro elemento que contribuyó a modificar los conceptos de libertad y ciudadanía asociados a los grupos de color fue el impacto de la revolución haitiana. Las noticias sobre las revueltas de los esclavos y las sucesivas fases revolucionarias de Haití circularon extensamente en los territorios de la América española - gracias a piratas, marineros, refugiados, exiliados y prisioneros-, favoreciendo la emergencia de un modelo político alternativo al de los privilegios ${ }^{14}$. La consecuencia de la gran revuelta haitiana no fue solo un endurecimiento del orden colonial y esclavista sino también la politización de los grupos de color de las sociedades de la costa. Algunas conspiraciones y sublevaciones de esclavos y libres de color en la Tierra Firme después de 1793 tenían como objetivos principales la libertad para los esclavos y el fin de las jerarquías raciales ${ }^{15}$.

Si el ejemplo haitiano fue positivo para los afro-descendientes de la región del Caribe, representó, por el contrario, una amenaza para las elites blancas materializada, por ejemplo, en la masacre de los blancos de la isla, perpetrada por Dessalines en el momento de la declaración de la independencia en 1804. Pero si antes de 1808 los eventos de la isla representaban para las elites hispano-americanas la triple amenaza de la revolución francesa, asociada a una peligrosa subversión de las legítimas jerarquías y a la guerra civil, en el momento de la constitución de las juntas autónomas, el precedente haitiano jugó a favor de un cambio de política con respecto al estatus jurídico de los libres de color. Después de 1810, en lugar de endurecer las jerarquías raciales, el ejemplo haitiano sirvió para justificar la integración política de los pardos a la ciudadanía. El temor de un conflicto de razas convenció a los

\footnotetext{
14 Scott, 1986. Dessens, 2007. Eller, 2011.

15 Gomez, 2008. Lasso, 2007: 28-33. Helg, 2004: 108-120.
} 
dirigentes republicanos respecto de la necesaria asociación al nuevo régimen a aquellos grupos capaces de provocar rebeliones. Eso explica, por ejemplo, por qué motivo la junta de Caracas pidió a los pardos de elegir representantes al momento de su formación: en lugar de excluir a priori los grupos mulatos y de color, se trataba de concederles una representación en el gobierno con el fin de neutralizar su supuesto deseo de revuelta contra los blancos. Esta voluntad de control social no debe sin embargo oscurecer la fuerte ruptura con el pasado: unos años atrás las elites criollas nunca hubieran aceptado esta medida, como demuestra la protesta del cabildo de la ciudad en 1795 de otorgar la igualdad jurídica a los pardos a través de las gracias al sacar ${ }^{16}$. El proceso revolucionario en Cartagena siguió el mismo modelo venezolano y la ciudad, que se había declarado independiente de España en 1811, extendió la ciudadanía a las castas. No obstante, las dos constituciones no enfrentaron la cuestión de la esclavitud, que de hecho no fue suprimida, siendo algunos pardos ricos propietarios de esclavos.

No obstante la importancia política de las constituciones de la época republicana, el acceso de los esclavos a la libertad y por ende a la ciudadanía se debe más bien a su participación en las guerras. En efecto, a partir del momento en el que estas se trasformaron de conflictos civiles entre ciudades a guerras internacionales contra los españoles, muchos esclavos fueron reclutados en ambos ejércitos (realista y republicano) en cambio de la liber$\operatorname{tad}^{17}$. Los esclavos eran generalmente preferidos a los indígenas porque, en contraste con estos, estaban disponibles para combatir en lugares alejados de su residencia habitual. El ejercito de los Andes de San Martín, por ejemplo, estaba compuesto por el $50 \%$ de esclavos y libres de color; en el caso de los ejércitos de Bolívar, el hecho de que la mayoría de los esclavos y castas de la Tierra Firme luchase del lado de los rebeldes significó la victoria definitiva sobre los españoles. Si bien la mayoría de los estados hispanoamericanos suprimieron definitivamente la esclavitud en la década de 1850, las guerras de independencia implicaron de hecho un fuerte debilitamiento de la institución, ya que millares y millares de esclavos se encontraron libres hacia el fin de los conflictos. Este resultado no se debe solo a la legislación independentista, que para atraer los afro-descendientes en los ejércitos insurgentes publicó importantes decretos que de hecho debilitaron la institución esclavista, sino también a la acción de los esclavos que, siguiendo una tradición bien arraigada en la colonia, negociaron o recurrieron en justicia para hacer efectivo sus derechos.

\footnotetext{
16 Herzog, 2003: 159-160.

17 Thibaud, 2003: 261 y ss.
} 


\section{ESCLAVITUD Y LIBERTAD EN UNA REGIÓN DE FRONTERA}

En el caso de una región de frontera, como la de Esmeraldas, la sociedad afro-americana se desarrolló de manera completamente distinta respecto de otras áreas del imperio español. Aun constituyendo la mayoría de la población como en la costa caribeña de Colombia y Venezuela, los afro-descendientes del área, tanto esclavos como libres, accedieron a la libertad y a la ciudadanía siguiendo pautas distintas de los de la costa septentrional del continente suramericano. Los grupos que vivían en este territorio fueron involucrados en el proceso de formación de milicias o en las guerras de independencia de manera muy indirecta y no fueron influenciados por los eventos haitianos. Sin embargo, las reformas y la crisis de la monarquía provocaron en esta región cambios tan importantes en la vida social de estos grupos que al final de las guerras de independencia su manera de percibir y acercarse a la libertad y a la ciudadanía se había transformado radicalmente. Sus acciones, como la de los afro-descendientes de otras regiones, contribuyeron a mutar las ideas sobre la libertad y la ciudadanía.

Ecológicamente, la región de Esmeraldas posee características propias de un complejo tropical-fluvial-húmedo de selva; este carácter permite mirar a ese área vinculada geográfica y culturalmente a una región mucho más extensa que comprende desde la provincia del Darién en Panamá, hasta la costa pacífica del norte de Esmeraldas, denominadas Tierras Bajas del Pacífico.

Durante buena parte de la época colonial fue una región de frontera, difícil de acceder, habitada por pobladores calificados de salvajes e incivilizados, marginal al estado y caracterizada por la escasa presencia de agentes de la corona, incluso los doctrineros. A los grupos nativos que conformaban la región (yumbos, cayapas, niguas, colorados y campaces) se añadieron, desde la mitad del siglo XVI, grupos de esclavos fugitivos victimas de naufragios. La presencia de esta nueva población modificó el cuadro étnico de la región favoreciendo la formación de grupos de zambos, producto del mestizaje afroindígena ${ }^{18}$. Más tarde estos mulatos, junto a la nueva población negra, resultado de nuevos naufragios, y especialmente aquella población que se desplazó del Pacífico sur colombiano a Esmeraldas en el transcurso de los siglos XVIII y XIX, dieron lugar a la conformación de las actuales poblaciones negras del norte del litoral ecuatoriano. Aunque a partir de la segunda mitad del siglo XVIII la región muestra una relativa vinculación económica y social a la sociedad colonial, desde el punto de vista político seguía conformando una región de frontera en el sentido de no estar bajo el control efectivo de la Corona y

\footnotetext{
18 Salomon, 1997.
} 
Mapa 1. Esmeraldas y las tierras bajas del Pacifico
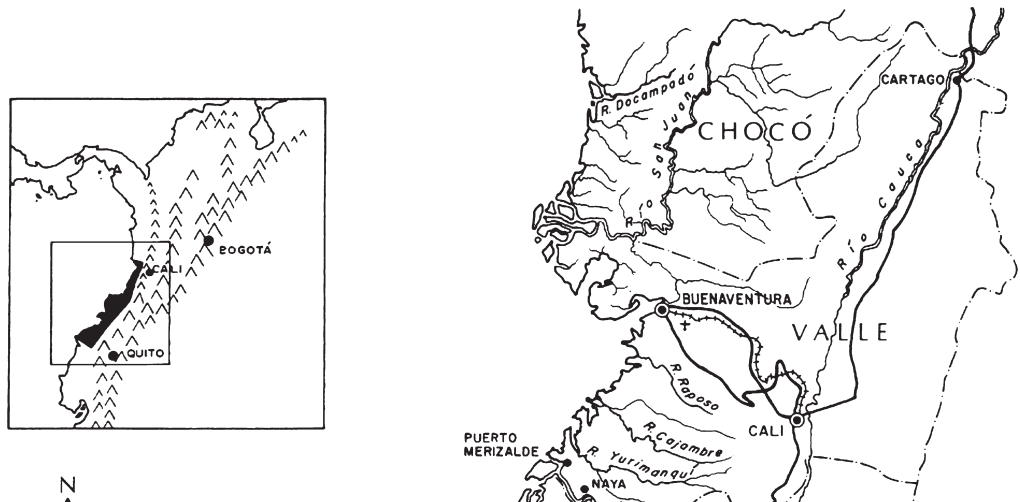

N
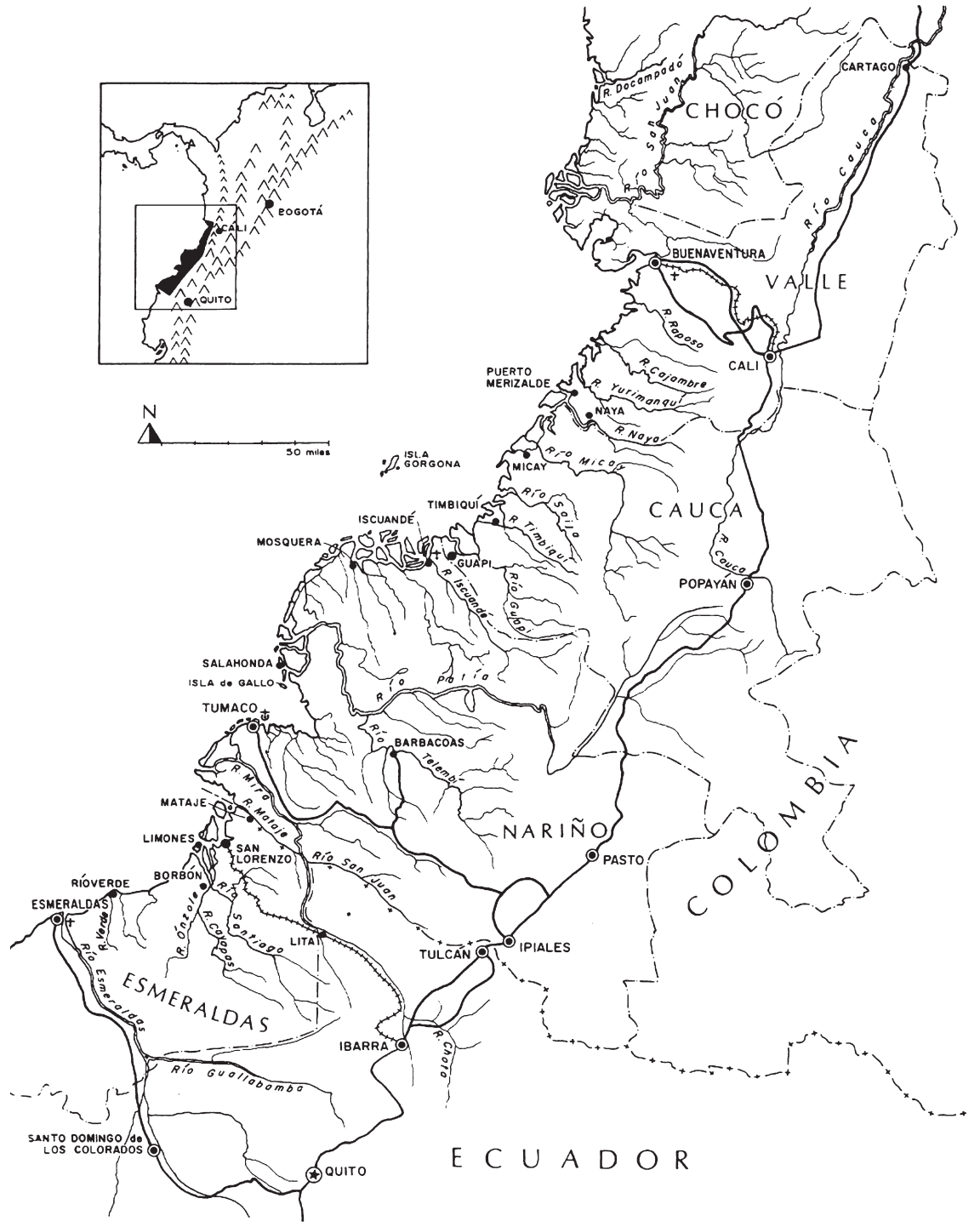

sus agentes, por falta de caminos que la vinculasen con los otros territorios de la Audiencia y más tarde con el Estado de Ecuador.

La presencia en la provincia de las Esmeraldas de indios «infieles y de guerra», y especialmente cacicazgos negros de conformación cimarrona que se 
reproducían social y materialmente en un territorio que, como producto de sus contiendas, extendía progresivamente sus fronteras fuera del control colonial, llevó a las autoridades españolas a iniciar acciones agresivas de conquista. Las expediciones tenían como objetivo someter a la población e incorporar sus territorios a la soberanía real con el fin de establecer encomiendas y aportes tributarios, pero el interés fundamental era aprovechar los beneficios económicos que podía proporcionar el comercio a través de Esmeraldas, considerada como un espacio geográfico estratégico ${ }^{19}$. Ubicada al noroccidente de los territorios de la Audiencia de Quito, en la costa pacífica, constituía el sitio más apto para abrir una vía terrestre y establecer un puerto que permitiera cumplir con el circuito comercial desde las tierras altas del área andina hasta el litoral pacífico. Desde este puerto era factible fomentar el intercambio de productos con Panamá, pues a la vez que se enviaban géneros agrícolas de los Andes, se recibían productos de Castilla. Esto explica el envío de múltiples provisiones reales en las que se facultaba a las autoridades la entrega de licencias a aquellos individuos interesados en colonizar y hacer una realidad el plan vial de la denominada «empresa de las Esmeraldas». Las autoridades y las élites quiteñas querían contar con una ruta más corta y económica de Guayaquil que permitiera trasladar en el menor tiempo las mercancías de los centros de producción andinos hacia la costa del Pacífico y desde allí a los diversos mercados, especialmente a Panamá. Más allá de las resistencias locales, los obstáculos que imponía un espacio cubierto de densa selva, el proyecto vial puesto en marcha durante el siglo XVII no llegó a concretarse debido además a factores de tipo externo, como la política de Madrid y de los virreyes de Lima, contraria a la construcción de nuevos caminos por la competencia comercial que suponía la apertura de un puerto en Esmeraldas frente a los puertos de Guayaquil y El Callao.

Con el siglo XVIII, las élites del interior andino, empeñadas en activar el comercio de exportación a través de Esmeraldas, intervinieron en medio de un contexto diferente generado por la nueva política centralizadora y mercantil adoptada por España a través del reformismo borbónico. La Audiencia de Quito, debido a la crisis del centro minero peruano, sector que permitió la activación económica de los diversos espacios coloniales, experimentó un escaso flujo monetario por la baja significativa en la producción textil, actividad dominante del corredor andino quiteño a partir del siglo XVII. Esta situación llevó a obrajeros y hacendados de la sierra centro-norte a insistir en el comercio con la metrópoli, Panamá y especialmente con los mercados mineros de Nueva Granada: el intercambio de productos agropecuarios y textiles por oro habría facilitado la monetización de la débil economía quiteña. Quien apostó por una empresa vial

19 Balboa, 2001: 45-75. 
fue el riobambeño Pedro Vicente Maldonado, un geógrafo y científico ilustrado que acompañó a Jorge Juan y Antonio de Ulloa en la misión de La Condamine (1734-1740), para medir el arco de la tierra en la línea equinoccial. Además como miembro de la élite de los hacendados y obrajeros y de la burocracia colonial, tenía varios intereses en empujar la abertura de un camino a Esmeraldas.

Una vez que el presidente de la Audiencia, Dionisio de Alsedo y Herrera, concedió a Maldonado licencia para iniciar la obra vial en 1735, se le otorgaron las mercedes correspondientes, entre otras, el nombramiento de gobernador y capitán general de la provincia de las Esmeraldas, puerto de Atacames y sus costas, para dos generaciones ${ }^{20}$. De forma inmediata, Maldonado trató de modificar la forma de vida de los habitantes de las tierras bajas de Esmeraldas (indios, negros, zambos, mulatos), adoptando para ello una serie de providencias tendientes a controlar la población y fundar nuevos pueblos. Se inició así una nueva fase de conquista de estas geografías de tierras calientes, mediante un proceso de pacificación, reducción y colonización de la región. Se formó un entramado de asentamientos como sólidos puntos de apoyo para la habilitación de las vías y se establecieron nuevas poblaciones como El Nuevo Embarcadero en el río Esmeraldas, la Tola y Limones, ubicadas en la desembocadura del río Santiago. Estos nuevos centros nucleados se poblaron con indios, mulatos y negros, que vivían dispersos en ríos y esteros como parte del tradicional patrón de asentamiento de selva. En un afán colonizador se convocó a la población de Iscuandé para incrementar la población de La Tola y se trasladó desde Quito a «delincuentes y ociosos» para habitar el puerto de Atacames. El progreso en la vía de Malbucho, más la noticia de la presencia de minerales de oro en los ríos Santiago y Mira, motivaron a Maldonado a convocar a mineros de Nueva Granada y de Quito para iniciar la explotación aurífera. Se abrió así una primera fase minera, con mineros de Tumaco, Cali, Popayán y Barbacoas que solicitaron al gobernador de Esmeraldas la concesión de tierras realengas para iniciar el entable de las minas y la licencia necesaria para introducir ganado para la manutención de las cuadrillas de esclavos que se pretendían trasladar ${ }^{21}$.

A pesar de todos estos esfuerzos, el nuevo proyecto vial resultó un fracaso: las razones de este malogro se encuentran, al igual que en el siglo anterior, en los obstáculos que impuso la difícil geografía y ante todo en las acciones de los diversos actores locales, como la resistencia de los varios grupos étnicos frente a los cambios profundos ocurridos en sus sociedades. La nueva

\footnotetext{
${ }^{20}$ Auto dictado por la Audiencia de Quito sobre apertura del camino de Esmeraldas a Ibarra, Quito, 1739-XI-6, en Rumazo González, 1948, t. I: 144-145.

${ }^{21}$ Rueda Novoa, 2010: 86-87.
} 
penetración hispana a la región, en efecto, implicó un proceso de ocupación y poblamiento de españoles, mestizos e indios de la sierra: se fundaron pueblos, se movilizó de manera forzada a la población local ubicándola en nuevos espacios al servicio del camino, y en general se desarticularon sus formas de producción económica, social, cultural y los términos de relación con el medio natural. Todo esto motivó a los indígenas y africanos a abandonar las tareas asignadas, dejaron los pueblos de reciente creación como el Nuevo Embarcadero, La Tola, Limones, y se reapropiaron de sus espacios conformados por territorios de selva, ríos y esteros.

Hacia final de la colonia, la política del presidente Héctor de Carondelet (1799) contempló la reactivación del proyecto vial por Malbucho, el cual se convirtió en el eje vertebrador de un proyecto económico y político auspiciado por las élites norandinas. Los mineros establecidos en la cuenca del río Santiago, especialmente, los señores de minas neogranadinas como los Arroyo, Valencia, Quintero, Landázuri, apoyaron el proyecto comercial de exportación y apertura de un camino por la ruta del norte. Si bien no descartaba su interés por la explotación aurífera, la principal motivación fue contar con un camino que les permitiera abastecerse de géneros para asegurar la subsistencia de las cuadrillas de sus distritos auríferos y obtener una alta rentabilidad minera. Al finalizar el siglo XVIII, el distrito minero del río Santiago se conformó en torno a cuatro grandes reales de minas: Playa de Oro, San Antonio de Cachavi, Nuestra Señora de la Purísima Concepción del río Bogotá y Nuestra Señora de la Concepción de Guembi, que albergaban cuadrillas con alrededor de 400 esclavizados provenientes de las minas de la región de Popayán ${ }^{22}$.

Las cuadrillas estaban conformadas por familias criollas, lo que significa que sus miembros habían nacido en las colonias españolas. Estas familias, con base en el patrón español de organización, eran resultado de la unión conyugal monogámica, patrilineal impulsada por la labor misionera en cumplimiento a lo establecido en los códigos, instrucciones y reglamentos respecto a los derechos de los esclavos, todo esto con el afán de evitar el concubinato interracial y el amancebamiento ${ }^{23}$. En los mercados de Popayán esta práctica de vender cuadrillas con familias enteras para los centros mineros se fue generalizando conforme avanzaba el siglo XVIII, pues se crearon vínculos de

${ }^{22}$ Rueda Novoa, 2001: 17.

${ }^{23}$ De acuerdo al capítulo VI de la Instrucción de 1789, los mineros debían promover el matrimonio entre los esclavizados. El dueño del esclavo debía comprar a la esclava en matrimonio. De esta manera, además de contribuir a su multiplicación, se evitaba la tendencia de los esclavizados hacia la promiscuidad. Lucena Salmoral, 1994: 111. 
parentesco que para los esclavistas resultaba beneficioso, ya que, a la vez que se aumentaba el rendimiento, éste podía ser un elemento de disuasión para evitar la huida de los esclavos. En la visita realizada a los reales de minas en 1815 , se contabilizó alrededor de 400 esclavos de un total de 2.300 habitantes existentes en Esmeraldas ${ }^{24}$. Los padrones levantados de los reales de minas en 1815 revelan la presencia de matrimonios donde constan los integrantes de las familias (madre, cónyuge e hijos), así como madres solteras con sus hijos y viudas. Paralelo al patrón español establecido respecto al matrimonio, funcionaron otras formas de convivencia en torno a las madres solteras que junto a sus hijos formaron familias, en las que el reconocimiento de la descendencia se realizaba por vía materna. Una práctica que fortaleció la autoridad y presencia de la mujer dentro de la familia. En algunos reales no era novedad que, frente al limitado número de mujeres, éstas iniciaran relaciones sexuales múltiples dando lugar a lazos de parentesco reconocidos por línea materna, lo que favoreció la familia extensa ${ }^{25}$.

En los registros documentales sobre los reales de minas, donde constan las familias con los apellidos, al inicio, aparecen los nombres de uno o dos capitanes de cuadrillas, que eran esclavos, generalmente mulatos o criollos, escogidos por el amo por sus dotes de liderazgo y reconocimiento dentro del grupo; tenían el encargo de difundir el castellano, hacer cumplir las normas de trabajo y el control social de los demás. Por lo tanto, en el seno de la sociedad esclavista se encontraban en un dilema: entre la defensa de los intereses del amo para el funcionamiento de los grupos de trabajo y la representación y amparo de la cuadrilla. Pero, además, velaban por los intereses de la Corona, pues en su presencia el minero pesaba la producción de oro para pagar el derecho de quintos que le correspondía al rey. Las leyes y reglamentos reales concedían además a estas cuadrillas un día libre la semana para el «descanso, la iglesia y con el fin de conseguir el sustento para el vestido». Las labores en este día dependieron de la iniciativa de los esclavos, quienes podían acceder a otras fuentes de proteínas para complementar la dieta, así como realizar pequeños cultivos junto a sus ranchos, cazar ciertos animales y recolectar frutos silvestres del bosque. Adicionalmente, los esclavos aprovechaban este día para recolectar oro en los ríos, oro que intercambiaban por productos que ofrecían los negros libres de la localidad y los comerciantes de Tumaco.

${ }^{24}$ Padrón de la población Tributaria de los reales de minas de Playa de Oro, Guimbi y San José de Cachavi (Esmeraldas, 24-XII-1815), Archivo Nacional del Ecuador (en adelante ANE), Serie Haciendas, caja 213, 1815, ff. 8-11.

${ }^{25}$ Romero Vergara, 1992: 18. 
El metal recolectado les permitió incluso llegar, en algunos casos, hasta la compra de su libertad.

Lamentablemente, no disponemos de muchas fuentes de archivo sobre esta región. Tratándose de un área de frontera, con una muy escasa presencia de autoridades civiles y religiosas, los pocos documentos que la conciernen son visitas pastorales, de gobierno, los inventarios de los Reales de Minas. Estos, además de ofrecernos datos sobre las cantidades de metal precioso producidas, nos proporcionan también algunos indicios sobre el trabajo de los esclavos y unos pocos aspectos de su vida cotidiana. Por ejemplo, en la visita realizada por el gobernador de Popayán ${ }^{26}$, don Pedro de Becaria y Espinoza, a los reales de minas de las provincias de Barbacoas e Iscuandé en 1779, encontró que los mineros no cumplían con su obligación de proveer a los esclavizados el vestuario y alimentación, como era su obligación de acuerdo con las normas establecidas en la colonias españolas ${ }^{27}$. Ante las dificultades de la rentabilidad de la actividad minera, esta obligación de los mineros se compensaba o se conmutaba, en general, por el permiso de los esclavos para trabajar todos los sábados para sí. Al concluir su visita, una de las recomendaciones principales del gobernador fue reconocer y legitimar que el trabajo para sí de los esclavos el sábado, nacido como costumbre, era una necesidad en toda la región, lo que de todas formas no eximía a los mineros de sus obligaciones para con sus esclavos, de acuerdo con las leyes de minas y demás disposiciones. A cambio de este reconocimiento, las cuadrillas y sus capitanes debían velar por las cantidades de oro efectivamente producidas por los Reales de minas para que los propietarios pagasen efectivamente el quinto a las cajas del estado.

Las autoridades coloniales conocían muy bien las dificultades de control efectivo que presentaba un sistema esclavista en un territorio de frontera, monopolizado por grupos de mineros blancos y sus poderes locales que no querían sujetarse a control alguno, en un entorno de selva húmeda tropical, con una economía especializada exclusivamente en la minería de aluvión, que se practicaba con cuadrillas de negros en condiciones de aislamiento y alta movilidad. Las rivalidades y tensiones entre las autoridades centrales (de Popayán o Quito), las autoridades locales y los mineros locales (que monopolizaban los cargos y el poder local), obligaron a las autoridades reales a conceder a los esclavizados una suerte de estatus de hecho con el fin de contrapesar, en parte, el poder omnímodo de los mineros en esta frontera. Las atribuciones

${ }^{26}$ A esta jurisdicción Esmeralda fue sometida durante varios periodos entre el final del siglo XVIII y el principios del XIX.

${ }^{27}$ Almario García, 2007: 201-204. 
conferidas a los esclavos configuran un «pacto no escrito» entre autoridades centrales y cuadrillas, que se explicaría por las condiciones sui generis de la esclavitud en la región: los esclavos debían contribuir a velar por el derecho al quinto real, mientras que el rey vigilaría, a través de sus funcionarios, que sus derechos como cristianos (trato, vestido, raciones, doctrina) fueran respetados por sus amos. Este pacto no puede ser comprendido sino en el contexto reformista de la segunda mitad del XVIII que, si bien quería hacer más efectivo el cobro de los impuestos, impuso también leyes y códigos que iban hacia una «protección» de los esclavos ${ }^{28}$.

La costumbre legitimada del trabajo los días sábados, además de los «días de guardar» (domingos o fiestas religiosas) permitió a los esclavos intensificar la explotación de los depósitos más productivos, volver sobre antiguos cortes abandonados por los mineros blancos por supuesto agotamiento y desplegar buena parte de su inventiva y conocimiento en torno a las actividades mineras. En esto parece confirmarse tanto por la frecuencia de expedientes sobre casos de auto-manumisión y compra de la libertad de familiares y relacionados, como por algunos pocos pero significativos casos en los que negros libres llegaron a apropiarse de minas, quebradas y ríos ${ }^{29}$. Ambos casos demuestran que los ex esclavos, aun de una región de frontera, conocían muy bien el funcionamiento y la maquina jurídica española. Además de un conocimiento perfecto del territorio, en los pleitos concernientes la reivindicación de las minas y las tierras a estas vinculadas demostraron de saber manejar perfectamente la cultura jurídica de la época, que reconocía a la posesión, el usufructo, a la familiaridad con el objeto, condiciones importantes para adquirir los derechos sobre las tierras ${ }^{30}$.

Aún sin la presencia de milicias o sin poder recurrir a mecanismos de ascenso político como el de «las gracias al sacar», la última fase de la época colonial implicó para los afro-descendientes de la región un mayor acceso a la libertad y a la ciudadanía. Si el pacto entre autoridades coloniales y cuadrillas había permitido a un buen número de esclavos conseguir la libertad mediante la auto-manumisión, los títulos sobre la tierra habían convertido a los libres de color en vecinos de la comunidad, permitiéndoles alcanzar un estatus social más elevado.

${ }^{28}$ Como medida preventiva para el cimarronaje, los Códigos, la Instrucción y los Reglamentos de la época borbónica contemplaron medidas sobre el cuidado y tratamiento de los esclavos, con objeto de evitar que los excesos de los amos les hicieran huir. Salmoral, 1996.

29 Morelli, 2015: 12-18.

${ }^{30}$ Ibidem: 22. Herzog, 2015: 34-42. 


\section{Guerras, LIBERTAD y CIUDADANÍA EN ESMERALDAS}

Las guerras de independencia cambiaron profundamente el panorama político y social de esta zona: el desorden y el caos de los conflictos, unidos a la falta de abastecimientos por la inhabilitación del camino y la huida de los esclavos, contribuyeron al paulatino abandono de las minas por parte de los dueños. La población de la región, si bien simpatizó desde el principio con la insurgencia, tuvo su propia dinámica y objetivo: los esclavos estaban dispuestos a defender una forma de vida construida con cierta autonomía y libertad a partir del debilitamiento de los dispositivos de explotación minera esclavista. Esto les permitió desplazarse libremente por los montes y los ríos, abandonar las labores mineras en beneficio de sus amos y decidir su colaboración al bando realista o insurgente. Una vez alineados con la insurgencia participaron como soldados, utilizaron la protesta social, la fuga y el uso libertario de formas de comunicación, provocando un ambiente de subversión y desconcierto.

Al momento de la primera fase de la independencia, o sea durante el periodo de las dos juntas quiteña, la de 1809 y la de 1810-12, los esclavos de Esmeraldas no se juntaron a los realistas, como habían hecho los de los Reales de Minas de Popayán. Como claramente ha demostrado Marcela Echeverri, la intención de los que se mantuvieron fieles a España era sustentar su búsqueda de libertad en el contexto monárquico. Apelaron abiertamente a la ilegalidad de la rebelión de sus amos, sentando como punto de partida su propia comprensión de la relación esclavista, en la que sólo era legítimo que se les mantuviera en ella mientras el rey estuviese a la cabeza de la misma; una vez rota esa jerarquía a causa de una rebelión anticolonial de sus amos, los esclavos no tolerarían permanecer bajo su yugo. Es decir, su definición de la servidumbre dependía enteramente del principio de legalidad ${ }^{31}$. Mientras en Popayán, la alianza entre los esclavos y los realistas durante la década de 1809-1819 se fortaleció por el hecho de que sus dueños, además de apoyar a los juntistas de Bogotá y Quito, no tenían intereses de negociar con ellos ofreciéndoles la libertad, en el caso de Esmeraldas los acontecimientos vinculados al destino de los revolucionarios quiteños cambió la suerte de los afro-descendientes. En este caso, en un contexto particular creado por la crisis de la Monarquía, en el que no solo los revolucionarios quiteños tuvieron que enfrentarse a las milicias realistas enviadas desde el Perú y Nueva Granada, sino que también se enfrentaron entre ellos, los esclavos opinaron más conveniente apoyar a los insurgentes, por lo menos en un primer momento. Sin

\footnotetext{
31 Echeverri, 2009: 58.
} 
embargo, su objetivo era el mismo de los esclavos de Popayán: aprovechar de la situación producida por la crisis para conquistar espacios de libertad.

Aún si el gobernador de Popayán, Miguel Tacón, intentó alistar algunos esclavos de la región en las milicias realistas para defender el puerto de la Tola, sito terminal de la ruta de Malbucho, a través de la cual se podía ingresar desde la costa hacia el interior andino, estos entraron en contacto directo con los insurgentes quiteños que, en cambio de su ayuda, le prometieron la libertad. La participación directa de los esclavos de estos reales de mina comenzó cuando Toribio Montes fue nombrado Presidente de la Audiencia de Quito en 1812, con lo cual el gobierno insurgente se trasladó a Ibarra y allí fue derrotado. El grupo de insurgentes, conformado entre otros por Nicolás de la Peña Maldonado, Joaquín Montúfar y el coronel Ramón Chiriboga, a raíz de la derrota, se convirtieron en fugitivos refugiándose en la selva de Malbucho con el propósito de salir a Buenaventura y reunirse con los ejércitos revolucionarios colombianos. Según Andrés de Castro, gobernador de Esmeraldas, este grupo entró en contacto con los esclavos y se encontraron en las minas, desde donde esperaban la llegada de sus compañeros; señaló, además, que no pude ir en su captura por cuanto «los negros ponen muchas trabas y rinden la vista por los quiteños ${ }^{32}$. Los insurgentes fueron derrotados a la Tola y conducidos a Tumaco, donde se instruyó el sumario y mas tarde se les ajustició. Sin embargo, el estado de insurrección no había terminado en las minas, pues en 1814 se conoció de un proyecto de fuga colectiva que pretendían realizar los esclavos para incorporarse a la comunidad fugitiva establecida en las montañas de Malbucho y en el río Tululbí, un refugio de esclavos huidos de las haciendas del valle del Chota, de las minas del sur colombiano y de los esclavos del distrito minero de Esmeraldas que trabajaban en los proyectos viales. Durante esta época, la zona se convirtió en efecto en un territorio de tránsito de esclavos, que huían en medio del fragor de los enfrentamientos, y en un lugar de cimarronaje itinerante y de bandolerismo ${ }^{33}$.

Una vez que los realistas retomaron el poder en la Audiencia de Quito en 1814, frente al creciente estado de insurrección del área y al total abandono de las minas, el gobernador de Esmeraldas Andrés de Castro, con el fin de someter a los rebeldes, decidió cambiar de estrategia: visitó los reales de Playa de Oro, Cachavi y Guembi y tomó posesión de las minas, pues en ausencia de los legítimos dueños estos bienes eran propiedad del rey. La intención era poner los esclavos a trabajar, pues la improductividad y la falta de sujeción en que vivían

32 Oficio de don Andrés de Castro al presidente Toribio Montes (Esmeraldas, 12-I-1813), ANE, Fondo Especial, caja 194, t. 473, ff. 91-92.

${ }^{33}$ Chaves, 2010: 139-141. 
habían provocado numerosas pérdidas al Estado. La descripción que presenta Andrés de Castro sobre el estado de las minas es de un completo deterioro ${ }^{34}$. Los esclavos también se quejaron del estado de pobreza en que se hallaban los reales de minas a causa de las continuas inundaciones de los ríos, hecho que ameritaba la construcción de nuevas pilas, estanques, acequias, capillas e iniciar nuevas siembras, sin lo cual era imposible la explotación minera. Este tipo de quejas permitían a los esclavos subrayar a las autoridades coloniales que sus amos no les protegían como estaba establecido en las leyes y por lo tanto que su dominio podía ser puesto en discusión. Para remediar esta situación, propusieron al gobernador un acuerdo que consistía en pagar una pensión o jornal cada seis meses en beneficio del rey, en San Juan y Navidad, fechas establecidas para el pago de tributos de los indios a la Corona; a cambio los esclavos tenían el usufructo y control de las minas, podían obtener oro de los lechos de los ríos o de los aluviones ribereños y continuaban en posesión de la tierra y con sus espacios de vida comunitaria y autónoma. La propuesta de los esclavos de transformarse en arrendatarios de las minas fue aceptada por el gobernador no solo por la dificultad de acceder y controlar efectivamente esos territorios, sino también porque, en cambio, los esclavos hubieran defendido el área contra los rebeldes y contribuido a las cajas estatales. Al final de 1815, en el libro de la Real Hacienda, el mismo Castro registró en efecto el ingreso de 1.100 pesos por la pensión de los negros de las minas ${ }^{35}$. Esta modalidad ya se utilizaba en otras regiones de la costa pacífica colombiana, en donde los afro-descendientes adquirieron el nombre de «mazamorreros»: éstos pagaban una cantidad por el «derecho de mazamorrería» y lo hacían dos veces al año, en San Juan y Navidad. Lo que vale la pena subrayar es que generalmente se trataba de grupos separados de la esclavitud y que podían acoger a otros libres $^{36}$. Por lo tanto, es probable que esta nueva condición asumida por los esclavos del distrito de Esmeraldas hubiera favorecido el acceso a la libertad por parte de numerosos esclavos de las minas.

Con el triunfo de Bolívar y las fuerzas patriotas en el puente de Boyacá, en el agosto de 1819, las campañas para la liberación definitiva de la monarquía española cobraron fuerza hacia el sur. Esto motivó un intenso tráfico marítimo de naves «piratas», calificativo que se daba a los barcos insurgentes que

${ }^{34}$ Expediente promovido por el Teniente de Gobernador de la ciudad de Esmeraldas Don Andrés de Castro, relacionándose a la visita efectuada a las minas del Río Santiago y Playa de Oro (Esmeraldas, 1815-I-1819) ANE, Fondo Especial, caja 207, tomo 510, ff. 134-140.

${ }^{35}$ Expediente relativo al inventario, avalúo y más diligencias practicadas para el remate de la hacienda nombrada La Molina en la jurisdicción de Esmeraldas (Esmeraldas, 16 de diciembre de 1815), ANE, Tierras, caja 213, exp. 16-XII-1815, f. 6.

36 Romero, 1995: 86. 
actuaban desde Colombia hasta Chile y que veían la participación de soldados americanos, ingleses, portugueses, africanos, chilenos y algunos españoles. Cuando estos soldados, con las fuerzas procedentes de Iscuandé, llegaron a Esmeraldas, los libres de color de los pueblos de esta ciudad, Atacames, La Tola y Río Verde se juntaron a los revolucionarios dando lugar a la independencia de la región.

El ambiente libertario forjado durante la segunda fase de independencia con la activa participación de la población libre de color, sin descartar la colaboración de los esclavos, dio continuidad a la dinámica interna de inestabilidad e inseguridad en la región. Después de años de autonomía y libertad, los afro-descendientes ya no estaban dispuestos a soportar la sujeción y el trabajo sistemático que requería el sistema esclavista. Su intención política era terminar con las antiguas relaciones de sujeción esclavista en la región, continuar con el control y laboreo de las minas y obtener del nuevo Estado la legitimación de sus sociedades mediante el reconocimiento de su condición de libres y de la propiedad de la tierra. Las practicas de manumisión forzadas por la guerra y aquellas que se aplicaron en cumplimiento de la ley de libertad de vientres contribuyeron a modificar el concepto de libertad de los esclavos, introduciendo un nuevo elemento en su universo de significación pública, el de que la libertad era una consecuencia de las transformaciones políticas, que debía ser unilateral y que constituía un derecho. En efecto, en los años siguientes a la independencia, los esclavos iniciaron múltiples acciones en los tribunales en contra de sus amos en demanda de la libertad, pues luego de ser parte de los ejércitos solicitaron el cumplimiento de los decretos emitidos por los libertadores. Procesos judiciales que en muchos casos dieron la razón a los esclavos ${ }^{37}$.

En 1826, frente al tentativo de los dueños de las minas de reapropiarse de sus bienes, los capitanes de las cuadrillas, Justo y Cornelio Arroyo, Agustín y Guillermo Valencia, y más tarde los capitanes Pío y Félix Valencia y Manuel Feliciano y Tomás Valencia, conocedores de la normativa jurídica colonial y de las ideas libertarias que pregonaba la nueva república, en un acto de resistencia legal, presentaron al protector general de esclavos, un documento con varias peticiones orientadas a defender un modo de vida que habría garantizado la subsistencia de los afro-descendientes como libres ${ }^{38}$. Para impedir que vol-

\footnotetext{
37 Véase los expedientes de los fondos Esclavos, Civiles y Notarías del Archivo Nacional del Ecuador a partir de 1822.

38 Recurso presentado por los capitanes de cuadrilla de los esclavos de las minas de Playa de Oro, San José y Guimbi del cantón Esmeraldas, por el abandono moral y material en que viven y por las extorsiones que padece por parte de los representantes de unos desconocidos amos (Quito, 10- IV-1826), ANE, Serie Esclavos, caja 23, exp. 3.
} 
vieran bajo el control de sus amos y administradores, los esclavos pidieron un mejoramiento de sus condiciones de vida y de trabajo (la provisión de herramientas, alimentación, vestido y días libres), el nombramiento de un capellán que les ayudase a recobrar la moral religiosa y que los dueños no enviaran comisionados a oprimirlos para reclamar sus derechos. Sin embargo, en este caso, no invocaron solo sus «libertades consuetudinarias», fundadas en la legislación de Antiguo Régimen, sino que se refirieron también al nuevo concepto de libertad solicitando la aplicación de los decretos expedidos por el poder Ejecutivo y en referencia presumiblemente a la ley de Libertad de Vientres, establecida en el Congreso de Cúcuta el 21 de julio de 1821. No obstante la vigencia de esta ley, fueron los recursos judiciales de los esclavos interpuestos en los juzgados los que la hicieron aplicable en el territorio. Ello significaba que, en continuidad con el Antiguo Régimen y con la naturaleza jurisdiccional del mismo, leyes y constituciones, aún en la época republicana, no se aplicaban automáticamente sino que requerían de la intermediación e interpretación de los jueces ${ }^{39}$.

En la parte final del documento los capitanes rechazaban el calificativo de «alzados» otorgado por las autoridades de gobierno. Esta imagen que se tenía de los esclavos, de alzados y subversivos, obedecía a las continuas acciones de resistencia que habían emprendido, entendidas como transgresoras del orden colonial. Aun si las autoridades y los propietarios caracterizaban estas acciones colectivas como actas de rebelión e insubordinación, en realidad los esclavos no se estaban rebelando contra las autoridades coloniales o intentando liberarse de la esclavitud. Más bien recurrían a la justicia para obtener la aplicación de las leyes y la protección del Estado. Este imaginario de la peligrosidad de los esclavos se había exacerbado no solo por el clima de rebelión en que se habían mantenido durante esos años, sino también por la capacidad que habían adquirido de enfrentar judicialmente el poder de los amos: acudir a los tribunales, movilizar redes de apoyo para mantener largos juicios y obtener la colaboración de diversos individuos pertenecientes a varios niveles de la sociedad.

Estas mismas prácticas permitieron además la construcción de una identidad forjada en la resistencia en un territorio de frontera, al que ellos denominaron el «patrio suelo». Un «suelo patrio» que se negaban a abandonar como pretendían las autoridades al sacar a los líderes rebeldes y trasladarlos a Tumaco. Acatar esa pretensión significaba el desarraigo del territorio y la desarticulación de las familias, ya que había sido en ese espacio donde se habían fortalecido los vínculos de parentesco en respuesta al sistema social

\footnotetext{
39 Lorente, 2007.
} 
de dominio esclavista. Este sentimiento de rechazo a la dispersión familiar y al destierro no afloraba solo entre los esclavos de la minas de Esmeraldas, sino también en los de las haciendas del valle del Chota-Mira y de las áreas urbanas ${ }^{40}$. No se trataba simplemente de un rechazo al abandono de la familia, porque la invocación del término «patria» hacía referencia a una transformación de la relación de los esclavos con el cuerpo político y social. Mientras la relación de dominio descansaba, entre otras cosas, sobre la incapacidad de los esclavizados de «representar figura en la república» ${ }^{41}$, después de las guerras de independencia los afro-descendientes tenían las expectativas de integrarse a un ideal de ciudadanía y de patria. Aunque este se fundaba todavía en una imagen territorial y corporativa de la nación, la idea de ser parte de una comunidad política territorializada cambió radicalmente el concepto de libertad. Si a esto añadimos la ausencia de caminos, por lo menos durante la primera mitad del siglo XIX, y la baja rentabilidad de las minas, que condujo muchos propietarios a abandonar el territorio, entendemos cómo las tierras se mantuvieron en las manos de los esclavos y de los libres de color.

Para finalizar, los esclavos de Esmeraldas en las contiendas por la independencia, se mostraron políticamente activos, afectando con su participación la serie de acontecimientos que caracterizaron esta región. Mediante un repertorio de comportamientos políticos, como el cimarronaje, la negociación, el enfrentamiento violento, la propagación de rumores o el litigio judicial, lucharon por llevar adelante un proyecto que suponía preservar su reproducción material y su autonomía. Sin embargo, su papel se entiende solo dentro de un contexto, el de la crisis de la monarquía y de las guerras, que había cambiado radicalmente la situación ofreciendo a los afro-descendientes instrumentos para conseguir la libertad y la ciudadanía. Los conflictos entre realistas e insurgentes, como ya las reformas en la segunda mitad del siglo XVIII, determinaron en esta región de frontera del imperio español una situación muy particular: gracias a algunos mecanismos (el trabajo en cuadrillas, los días de descanso, el usufructo de las tierras en cambio de impuestos) y a la ausencia de propietarios y de autoridades coloniales, las tierras y los recursos estaban de hecho bajo el control y la gestión de los esclavos, aun antes que estos accedieran a la condición de libres. Lo que les ofreció no solo la posibilidad de obtener la libertad, sino de transformarse en propietarios de estos mismos territorios.

Al mismo tiempo, las guerras y las proclamas de los libertadores a favor de la libertad, favorecieron la transformación de este concepto para los esclavos: de un privilegio otorgado por el amo a un derecho político vinculado a la

\footnotetext{
40 Chaves, 2010: 145.

${ }^{41}$ Chaves, 2001: 154-155.
} 
ciudadanía. Dado que la constitución de Cúcuta de 1821, como la mayoría de las constituciones independientes, basó los derechos políticos en el antiguo concepto de vecindad (la introducción de una barrera censual siendo compensada por el ejercicio de una profesión independiente), la posesión de las tierras asumía un papel importante para acceder a la ciudadanía. Los afro-descendientes aprendieron no solo a utilizar los recursos de la justicia para obtener la libertad y el control de la tierra, sino a usar los instrumentos y lenguajes políticos republicanos para lograr una paridad política y jurídica con los blancos.

\section{BiBLIOGRAFÍA}

Adelman, Jeremy, Sovereignty and Revolution in the Iberian Atlantic, Princeton, Princeton University Press, 2006.

Almario, Oscar, "Territorio, etnicidad y poder en el Pacífico sur colombiano 17801830 (Historia y etnohistoria de las relaciones interétnicas)", Tesis de doctorado en Antropología, Universidad de Sevilla, 2007.

Andrews, George R., "The Afro-Argentine Officers of Buenos Aires Province 18001860", Journal of Negro History, 64/2 (New Orleans, 1979): 85-100.

Andrews, George R., Afro-Latin America, 1800-2000, Oxford-New York, Oxford University Press, 2004.

Annino, Antonio; Guerra, François-Xavier y Castro Leiva, Luís, "Epilogo: Diálogo a tres voces", A. Annino, F.-X. Guerra y L. Castro Leiva (eds.), De los imperios a las naciones: Iberoamérica, Zaragoza, Ibercaja, 1994: 613-615.

Balboa, Miguel, Descripción de la Provincia de Esmeraldas, Madrid, CSIC, 2001.

Baylin, Bernard, Atlantic History: Concept and Contours, Cambridge (MA), Harvard University Press, 2005.

Blanchard, Peter, Under the Flags of Freedom: Slave Soldiers and the Wars of Independence in Spanish South America, Pittsburgh, University of Pittsburgh Press, 2008.

Bohiga, Nuria Salas de, Sobre esclavos, reclutas y mercaderes de quinto, Barcelona, Ariel, 1974.

Chaves, Maria Eugenia, Honor y libertad: Discursos y recursos en la estrategia de libertad de una mujer esclava (Guayaquil a fines del periodo colonial), Gotemburgo, Universidad de Gotemburgo, 2001.

Chaves, Maria Eugenia, "Esclavizados, cimarrones y bandidos. Historia de la resistencia en el valle de Chota-Mire, en el contexto de la revolución de los marqueses quiteños", H. Bonilla (ed.), Indios, negros y mestizoas en la independencia, Bogotá, Planeta, 2010: 130-149. 
Dessens, Nathalie, From Saint-Domingue to New Orleans: Migration and Influence, Gainesville, University Press of Florida, 2007.

Dym, Jordana, From Sovereign Villages to National States. City, State, and Federation in Central America, 1759-1839, Albuquerque, University of New Mexico Press, 2007.

Echeverri, Marcela, "Los derechos de indios y esclavos realistas y la transformación política en Popayán, Nueva Granada (1808-1820)", Revista de Indias, 69/246 (Madrid, 2009): 45-71.

Eller, Ann, "All Would Be Equal in the Effort: Santo Domingo's Italian Revolution, Independence, and Haiti, 1809-1822", Journal of Early American History, 1 (Leiden, 2011): 105-141.

Games, Alison, "Atlantic History: Definitions, Challenges, and Opportunities", The American Historical Review, 111 (Chicago, 2006): 741-757.

Geggus, David P. (ed.), The Impact of the Haitian Revolution in the Atlantic World, Columbia, University of South Carolina Press, 2001.

Geggus, David P., "The Caribbean in the Age of Revolution", D. Armitage y S. Subrahmanyam (eds.), The Age of Revolutions in Global Context, c. 1760-1840, New York, Palgrave Macmillan, 2010: 83-100.

Gómez, Alejandro, "La Revolución de Caracas desde abajo", Nuevo Mundo Mundos Nuevos, 2008. http://nuevomundo.revues.org/32982 Fecha de consulta: 2/7/2015.

Gómez, Alejandro, Le spectre de la Révolution noire: l'impact de la Révolution haïtienne dans le monde atlantique, 1790-1886, Rennes, Presses Universitaires de Rennes, 2013.

Guerra, François-Xavier, Modernidad e Independencias: ensayos sobre las revoluciones hispánicas, Madrid, MAPFRE, 1992.

Halperín Donghi, Tulio, Reforma y disolución de los imperios ibéricos, Madrid, Alianza Editorial, 1985.

Hancock, David, "The British Atlantic World: Co-ordination, Complexity and the Emergence of an Atlantic Market Economy, 1651-1815”, Itinerario, 23 (Leiden, 1999): 107-126.

Helg, Aline, Liberty and Equality in Caribbean Colombia, 1770-1835, Chapel Hill, University of North Carolina Press, 2004.

Herzog, Tamar, Defining Nations. Immigrants and Citizens in Early Modern Spain and Spanish America, New Haven - London, Yale University Press, 2003.

Herzog, Tamar, Frontiers of Possession. Spain and Portugal in Europe and the Americas, Cambridge (MA), Harvard University Press, 2015. 
Johnson, Lyman, Workshop of Revolution: plebeian Buenos Aires and the Atlantic world, 1776-1810, Durham, Duke University Press, 2011.

Lasso, Marixa, Myths of Harmony: Race and Republicanism during the Age of Revolution, Colombia 1795-1831, Pittsburgh, University of Pittsburgh Press, 2007.

Lorente, Marta, "Las resistencias a la ley en el primer constitucionalismo mexicano", C. Garriga y M. Lorente, Cádiz, 1812. La Constitución jurisdiccional, Madrid, Centro de Estudios Politicos y Constitucionales, 2007: 393-420.

Lucena Salmoral, Manuel, Los códigos negros de la América española, Alcalá de Henares, UNESCO/Universidad de Alcalá, 1996.

Morelli, Federica, "Entre ancien et nouveau régime", Annales. Histoire, Sciences Sociales, 59/4 (Paris, 2004): 759-81.

Morelli, Federica, Territorio o Nación. Reforma y disolución del espacio imperial in Ecuador, 1765-1830, Madrid, Centro de Estudios Políticos y Constitucionales, 2005.

Morelli, Federica, "Terra e libertà. I liberi di colore in una regione di frontiera (Popayán-Esmeraldas, secoli XVIII-XIX)”, Quaderni storici, I (Bolonia, 2015): 145-174.

Pinto, Carmine (ed.), "Crolli borbonici”, Meridiana. Rivista di Storia e Scienze Sociali, 81 (Roma, 2014): 9-168.

Rodríguez, Jaime E. (ed.), Mexico in the Age of Democratic Revolutions, 1750-1850, Boulder, Lynne Rienner Publishers, 1994.

Rodríguez, Jaime E., La independencia de la América española, México, Fondo de Cultura Económica, 1996.

Romero, Diego Mario, "Procesos de poblamiento y organización social en la costa pacífica colombiana", Anuario colombiano de historia social y de la cultura, 1819 (Bogotá, 1992): 9-31.

Romero, Diego Mario, Poblamiento y Sociedad en el Pacifico colombiano, siglos XVI al XVIII, Cali, Universidad del Valle, 1995.

Rueda Novoa, Rocío, "Esclavos y negros libres en Esmeraldas, s. XVIII-XIX”, Procesos. Revista ecuatoriana de historia, 16 (Quito, 2001): 3-33.

Rueda Novoa, Rocío, “De esclavizados a comuneros en la cuenca aurífera del Río Santiago-Río Cayapas (Esmeraldas). Etnicidad negra en construcción en Ecuador siglos VIII-XIX", Tesis de doctorado, Universidad Andina Simón Bolívar, Quito, 2010.

Rumazo, José (ed.), Documentos para la Historia de la Audiencia de Quito, 8 tomos, Madrid, Afrodisio Aguado, 1948.

Salomon, Frank, Los yumbos, niguas y tsátchilas o "colorados” durante la colonia española: etnohistoria del occidente de Pichincha, Quito, Abya-Yala, 1997. 
Scott, Julius, The Common Wind: currents of Afro-American communication in the era of the Haitian Revolution, Ann Arbor, University of Michigan, 1986.

Thibaud, Clément, Republicas en armas. Los ejércitos bolivarianos en la guerra de Independencia en Colombia y Venezuela, Bogotá, Planeta, 2003.

Thibaud, Clément; Entin, Gabriel; Gómez, Alejandro y Morelli, Federica (eds.), L'Atlantique révolutionnaire. Une perspective ibéro-américaine, Paris, Les Perséides, 2013.

Tío Vallejo, Gabriella, Antiguo Régimen y liberalismo. Tucumán, 1770-1830, Tucumán, Universidad Nacional de Tucumán, 2001.

Fecha de recepción: 1 de septiembre de 2015.

Fecha de aceptación: 1 de diciembre de 2015.

\section{Wars, Freedom and Citizens. Afro-Descendants of Esmeraldas during the Independence}

The article analyzes the role played by the crisis of the Spanish empire and the SpanishAmerican wars of independence in the transformation of the social and racial hierarchies during colonial times, as well as the configuration of new social rights. This study of the case of Esmeraldas, a region on the on the north-east border of Ecuador, aims to shed light upon the various mechanisms the Afro-descendants, both slaves and free men, used in order to obtain freedom and as the Monarchy fell. The strategies employed differed from those used by slaves and free men in other parts of Latin America due to the specific dynamics that are characteristic of border regions.

KEY WORDS: colored free men; slaves; citizens; freedom; Esmeraldas. 